\title{
OPEN
}

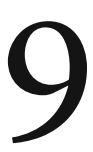

\section{Academic Libraries and Academic Books: Vessels of Cultural Continuity, Agents of Cultural Change}

Kate Price

Abstract: Academic books can deeply affect the ways that human beings perceive the world and interact with one another, playing an important role in cultural change. Academic libraries help to ensure that their contents are available to inform the thinking of future generations, playing an important role in cultural continuity.

This chapter argues that the academic book may evolve into something very different in the future, but that the passion of librarians for ensuring that books in whatever form are made freely available will continue to drive forward innovation and collaboration, even in the face of major social and technological changes.

Keywords: culture; digital preservation; ebooks; ethics; librarianship

Lyons, Rebecca E. and Samantha J. Rayner (eds). The Academic Book of the Future. Basingstoke: Palgrave Macmillan, 2016. DOI: 10.1057/9781137595775.0016. 
This chapter examines the role that academic books play in culture beyond the academy, and the ways in which academic libraries and librarians can support and challenge that role as books move into the next stage of their evolution.

The Oxford English Dictionary defines culture as 'the distinctive ideas, customs, social behaviour, products, or way of life of a particular nation, society, people, or period.' ${ }^{1}$ Whether an academic book appears as a traditionally published print-on-paper textbook, scholarly monograph or reference work, or as a more fluid digitally-produced work with interactive, collaborative or social media elements, it exists to encapsulate knowledge in some depth, and distribute it to all those who wish to learn from it, in the process becoming a powerful vector for the transmission of culture. However, the evolution of the academic book poses some major questions about the future role of both books and libraries in society.

\section{Academic books as agents of cultural change}

The fundamental quality of an academic book, in contrast to other forms of academic discourse such as the journal article or conference paper, is that it embodies a sustained and in-depth examination of a particular topic. Books are more suited to non-expert readership, as they allow the author space for full explanations which can move from the basic to the sophisticated within the course of a single work. This makes them particularly important as transmitters of new ideas within wider society as well as within the purely academic environment.

When an academic book is doing its job well, the author synthesises new and existing data and ideas into a cogent piece of work. The reader ingests these facts and concepts, and then a process of cognition takes place. The facts and concepts become transformed into wider knowledge, and a change occurs in the world as a consequence. The results may be quickly recognised at the individual level: the author may experience an increase in their academic reputation and gain a promotion; a student may be able to explain an idea that is new to them to a seminar group; a medical doctor may find the details of a new drug combination and use it to treat a patient; a member of the public may be inspired to pursue a topic further by visiting a historic site, and so on. 
However, the effects of academic books can be much more profound, producing transformative changes at the cultural level. To give a very brief and partial selection of examples, Newton's Principia Mathematica, Darwin's Origin of Species, Marx's Das Kapital, Greer's The Female Eunuch, and Carson's Silent Spring profoundly changed our perception of the mechanics of the physical universe, the genesis of humanity, the effects of capitalist economics on society, the way that the sexes relate to one another, and the human effect on the environment.

It is important to remember that texts such as these have never stood alone. Each author was able to draw upon centuries of existing intellectual discourse in written form, whilst also being able to debate their ideas with contemporaries. Readers continued to add to the debate long after publication, in both academic and public forums. Each text has become a node in a network of knowledge extending backwards and forwards in time, and crossing social and geographical boundaries. Over time (and with the help of academic libraries which continued to make them available), such texts have weathered controversy and strong opposition to become the foundation stones for today's cultural attitudes.

In the digital world, academic texts are potentially more available to the public than ever before, with a corresponding potential for more immediate and wider effects on cultures and societies. It is now possible to publish and disseminate texts through a number of different channels, including Open Access formats that require no payment from the reader. It is also possible to access a book review or citation in one digital publication, or to be alerted to the existence of a book by a social media network, and then immediately download the full text of the work onto a mobile device, or order a print version online for delivery within a few hours. Online forums allow readers and authors to engage in debate surrounding the content, bringing it very swiftly to the attention of an expanding audience.

Although wider access to books is facilitated by digital advancements, it can also be restrictive. The cultural influence of the academic book is not lost on governments and political groups that seek to control the perceptions and behaviours of populations. The banning and deliberate destruction of books and purging of libraries has occurred in different cultural contexts throughout the ages, as a means of imposing religious or political orthodoxies. In the digital arena, where there are no physical copies to purge, governments are able to restrict access to digital book content simply by preventing public internet access altogether, as in 
North Korea, ${ }^{2}$ or by filtering internet content using blacklisted terms, as with the 'Great Firewall of China.'

Deliberate denial of access to academic books for political reasons is extreme, but there are many other challenges that lie in the way of public engagement with academic texts in the digital arena. Individual poverty, local or national lack of investment in digital infrastructure, lack of digital book content available in local languages, lack of userfriendliness in ebook interfaces, volatility of formats and business models, impermanence of content, lack of interlinking between digital texts, and differences in intellectual property rights law between nations all throw up practical barriers to accessing academic books in new media.

In the meantime, social factors such as lack of familiarity with the use of digital media amongst demographic groups such as the elderly, ${ }^{4}$ a trend towards shallower engagement with online texts exemplified by the 'skimming' and 'bouncing' behaviours observed during the British Library's Information Behaviour of the Researcher of the Future project, ${ }^{5}$ and a tendency towards accessing the online 'snippets' of visual and audio based content eloquently described by Nicholas Carr in his book The Shallows, ${ }^{6}$ may lead to the inability of readers to make the most of the rich textual content to which they do have access.

Thus readers with less money, who live in poorly developed areas of the world, who are non-English speakers, who are less adept with online media, or who have less contact with long-form works in their previous experience are potentially even less likely to engage with academic books in the future than they are at present.

The issue of trust and quality also arises - readers may lack trust in content that does not bear a familiar brand, or conversely may be inclined to place too much trust in content that has been produced by pressure groups to reinforce the existing prejudices or exploit the vulnerabilities of their target audiences.

In the future, major challenges may also arise from the diversity and ephemerality of some of the discourse surrounding academic books. If it is important to be able to reconstruct the pathway of an argument by reading the original quotation in context, or correctly attribute the genesis of an idea, how might we access and cite these in the future when the content of social media is changing, and potentially disappearing, at an accelerating rate? 


\section{Academic libraries as vessels of cultural continuity}

In common with academic books, academic libraries have encountered both huge opportunities and huge challenges as a consequence of the internet revolution and the social changes that this has brought about.

Libraries (including national, university and college, learned society, and museum libraries) have played a critical role in the systematic collection and preservation of academic works for over two thousand years, and as such have been agents of cultural continuity, complementing the role that academic books play as agents of cultural change.

Academic libraries have also been pioneers, being amongst the first large organisations to harness the power of networked information dissemination, notably through the provision of online public access catalogues and online abstracting and indexing services such as IBSS (International Bibliography of the Social Sciences), which was produced by the British Library of Political and Economic Science at the London School of Economics between 1989 and 2010. However, over the last 20 years, the central role of libraries in the provision of academic information has been called into question by fast-developing internet services such Google, Wikipedia and Mendeley, which provide user-friendly conduits to academic texts without recourse to the library catalogue. These services, together with novel business models such as Open Access, have raised the possibility that the academic book of the future could be entirely de-coupled from the concept of the library collection. If this is the case, what are the implications for cultural continuity?

One of the defining characteristics of the academic library is that it curates a structured and quality-controlled collection of books suited to the needs of its specific audiences through cycles of selection, cataloguing and classification, physical or virtual arrangement, stock review, and relegation. In other words, curation is the process of deciding what to keep and how best to make it visible.

In the highly networked world of the academic book of the future, curation may appear to be irrelevant, as the physical location of a volume becomes unimportant and readers can find and use books directly from the authors' or publishers' websites. However, effective curation is hugely important when considering issues of cultural continuity, since born-digital information is at risk of loss almost as soon as it has been created, particularly if it includes social media elements, or if the technology upon which it is accessed becomes obsolete (consider, for 
instance, $\mathrm{CD}-\mathrm{ROMs})$. Also, the indiscriminate preservation of every single iteration of a fluid, digital text may render the core meaning of that text impossible to reconstruct at a later date.

To guarantee the long-term continuation of access to the fundamental message and meaning of the academic book of the future and its surrounding discourse, curatorial decisions need to be made on what elements should be retained at the time that the content is created, and arrangements need to be made for placing the content in a trusted repository. At present, there is no obvious way to do this systematically for all newly created digital works (particularly those which do not come to fruition via established publishing routes), to guarantee that this content will be discoverable in the future, or to ensure that such new works become situated in their academic and cultural context through backwards and forwards links.

Some publishers may place content into dark archiving services such as Portico and CLOCKSS to enable long-term preservation, as well as depositing the text with a national library. The Internet Archive and Hathi Trust also preserve digital books. The Directory of Open Access Books (DOAB) signposts peer-reviewed academic books published in Open Access formats, and thereby offers an element of quality control. CrossRef provides a clearing-house for links between works published online. Virtual distributed collections such as the European Library and the Digital Public Library of America (DPLA) showcase the outcomes of digitisation projects which may be preserved at individual institutions. OCLC's WorldCat service aims to provide a comprehensive global library catalogue. There is overlap or interplay between several of these services, which gives the sense of a patchwork of approaches to an evolving curatorial problem, without providing an overarching solution. However, the organisations that oversee and develop these services do provide possible models of governance, independent of individual author, institution or publisher interests, which could be built upon to provide systematic curatorial decision-making services for the future.

What is notable about the initiatives mentioned above is that although they do not bear the names of individual academic libraries, they have often been implemented as a result of issues highlighted by academic librarians, and continue to develop through the collaboration of librarians with other professional groups, across institutional and sectoral boundaries. The ethics and values of librarianship as a profession are instrumental in this approach. For example, the CILIP (Chartered 
Institute of Library and Information Professionals) Ethical Principles emphasises 'concern for the public good... including respect for diversity within society, and the promoting of equal opportunities and human rights', and as Professor Robert Darnton, up until recently Harvard's University Librarian, says of the DPLA, 'What could be more utopian than a project to make the cultural heritage of humanity available to all humans?'8

Such professional values have driven much of what has already been achieved in making academic books available online to ever wider audiences, and have moved some librarians to take strong positions on areas of concern ranging from Open Access and technical restrictions on the use of published text, to the provision of accessible versions of texts for disabled readers, many of which can be challenging for both authors and publishers. These professional values are the product of a particular culture (one of openness and inclusivity), and aim to continue it by providing a voice for current and future readers.

The emphasis on equitable access to information extends to the provision of facilities and support for the use of new forms of information. For example, King's College London makes available almost 200 laptop computers across six library sites to borrow free of charge to ensure that individuals are not disadvantaged if they cannot afford to purchase their own digital device, ${ }^{9}$ and Manchester University Library's 'My Learning Essentials' programme ${ }^{10}$ provides self-directed learning materials to assist students and researchers in assessing books' quality and relevance. In these and many other ways, libraries help readers to make full use of academic-book content, and thereby play a part in ensuring that the knowledge and understanding that books can provide continue to be part of our wider culture.

\section{Conclusion}

Academic books and academic libraries play important roles in the creation, transformation, and continuation of cultures and societies, informing the ways in which human beings perceive and interact with the world and one another. Although new means of communication, information provision and cultural expression may seriously challenge the position of books and libraries, it is likely that both will continue to evolve to meet those challenges. 
Librarians will be essential partners with the authors and publishers of the academic book of the future during this process of evolution: by raising their awareness of issues of fundamental cultural importance, and by working with them to ensure that the network of knowledge linking the past to the present and onwards into the future remains intact to inform the thinking of future generations, librarians will continue to be custodians of our intellectual, cultural, and creative heritage. In summary, because of the passion of librarians for ensuring that books in whatever form are made freely available to everyone, along with the means to make good use of them, there is reason to believe that academic libraries will continue to be vessels of cultural continuity well into the future.

\section{Notes}

1 Oxford English Dictionary (2015) 'Culture, n'. in OED Online [database] (Oxford: Oxford University Press), accessed 22 August 2015.

2 M. Sparkes (23 December 2014) 'Internet in North Korea: Everything You Need to Know', Daily Telegraph, http://www.telegraph.co.uk/technology/11309882/ Internet-in-North-Korea-everything-you-need-to-know.html, accessed 4 September 2015.

3 O. August (2007) 'The Great Firewall: China's Misguided - and Futile Attempt to Control what Happens Online', Wired Magazine, 15(11), http:// archive.wired.com/politics/security/magazine/15-11/ff_chinafirewall, accessed 4 September 2015.

4 For example, a recent study found that ' $44 \%$ of Americans aged 65 and older do not use the internet, and these older Americans make up almost half (49\%) of non-internet users overall'. K. Zichuhr (2013), Who's Not Online and Why (Washington, DC: Pew Research Center), http://www.pewinternet. org/2013/o9/25/whos-not-online-and-why/, accessed 4 September 2014.

5 I. Rowlands, D. Nicholas, P. Williams, et al. (2008) 'The Google Generation: The Information Behaviour of the Researcher of the Future', Aslib Proceedings, $60(4): 290-310$.

6 N. G. Carr (2010) The Shallows: How the Internet Is Changing the Way We Read, Think and Remember (London: Atlantic Books).

7 CILIP (2004) 'Ethical Principles', CILIP website, http://www.cilip.org.uk/cilip/ about/ethics/ethical-principles, accessed 22 August 2015.

8 R. Darnton (2013) 'The National Digital Public Library Is Launched!' The New York Review of Books, http://www.nybooks.com/articles/archives/2013/apr/25/ national-digital-public-library-launched, accessed 22 August 2015. 
9 Library Services, King's College London (2015) 'Laptop Loans for Students', http://www.kcl.ac.uk/library/using/loans/laptops.aspx, accessed 22 August 2015.

10 University of Manchester Library (2015) My Learning Essentials, http://www. library.manchester.ac.uk/services-and-support/students/support-for-yourstudies/my-learning-essentials, accessed 4 September 2015.

(c) (i) Except where otherwise noted, this work is licensed under a a copy of this license, visit https://creativecommons.org/version4 